\title{
Análise da Relação Entre As Condutas dos Profissionais Enfermeiros, Técnicos e Auxiliares de Enfermagem com Os Processos Éticos Profissionais Junto ao Coren Sp.
}

\author{
Penna, Moira Helena Maxwell; Cohen, Claudio; Oliveira, Reinaldo Ayer de \\ Bioética - Grupo de Pesquisa em Bioética, Direito e Medicina da Faculdade de Medicina da \\ Universidade de São Paulo - moirahelena@gmail.com
}

INTRODUÇÃO: Esse trabalho surgiu após observações das atitudes dos Profissionais de Enfermagem que me impeliram a investigar as questões que levam os profissionais de Enfermagem a serem denunciados ao Conselho Regional de Enfermagem de São Paulo - CORENSP. a enfermagem compreende um componente próprio de conhecimentos científicos e técnicos, construído e reproduzido por um conjunto de práticas sociais, éticas e políticas que se processa pelo ensino, pesquisa e assistência. Realiza-se na prestação de serviços à pessoa, família e coletividade no seu contexto e circunstâncias de vida. OBJETIVO: o presente estudo tem por objetivo quantificar o números de processos éticosprofissionais abertos e o de enfermeiros denunciados num período de quatro anos, de 2001 a 2004 , caracterizar os profissionais denunciados, os principais tipos de denúncia, os locais de ocorrrência das mesmas, analisar os resultados dos julgamentos dos enfermeiros denunciados, a possível apenação que Ihes foi aplicada e o tempo processual requerido. MÉTODO: Trata-se de uma pesquisa baseada na coleta de dados contidos nos prontuários dos processos ético-administrativo, no âmbito do COREN, por meio da utilização de um questionário. RESULTADOS: Os resultados numéricos foram tratados estatisticamente e os dados qualitativos por meio de análise de discurso. CONCLUSÃO: a maioria das ocorrências chegam ao CorenSP por meio de denúncia feita pelas CEEs, com relação à distribuição do número de descritores agrupados em tipos de infrações éticas envolvidos na denúncia, dos Processos Ético-Profissionais analisados houve uma predominância da iatrogenia $38,83 \%$ dentre os descritores dos processos analisados. a diferença entre a iatrogenia e o segundo colocado, falsidade ideológica foi de $49,32 \%$. As denúncias são feitas em sua grande maioria dentro de hospitais públicos, quando comparados com os hospitais privados demonstrando claramente o desnível da assistência oferecida por essas instituições, o que reflete no número de denúncias de infrações éticas. As denúncias entre a cidade de São Paulo e cidades do interior do estado de São Paulo de acordo com a pessoa jurídica (CEE) como parte denunciante indicam um maior número de denúncias feitas pelas Comissões de Ética de Enfermagem - CEEsdo interior do estado de São Paulo. As denúncias de pessoas físicas ocorreram no interior em $63,64 \%$ do estado de São Paulo e $36,36 \%$ na capital, indicando, portanto um maior número de denúncias feito por pessoa física no interior. As pessoas que denunciam $52 \%$ são pacientes, seguidos por acompanhantes $32 \%$. Os enfermeiros que denunciam foram $12 \%$. a maioria das pessoas físicas como parte denunciada foram os auxiliares de enfermagem em $55,56 \%$, enquanto enfermeiros foram denunciados $33,9 \%$. Isto significa uma diferença entre pessoa física do auxiliar de enfermagem em relação a enfermeiros de $86,05 \%$. com relação à distribuição dos artigos infringidos do Código de Ética dos Profissionais de Enfermagem, segundo o número e a porcentagem em ordem decrescente o artigo mais infringido, artigo 16, aconteceu em 11,13\%.

Penna, Moira Helena Maxwell; Cohen, Claudio; Oliveira, Reinaldo Ayer de. Análise da Relação Entre As Condutas dos Profissionais Enfermeiros, Técnicos e Auxiliares de Enfermagem com Os Processos Éticos Profissionais Junto ao Coren Sp.. In: Anais do Congresso Internacional de Humanidades \& Humanização em Saúde [= Blucher Medical Proceedings, num.2, vol.1]. São Paulo: Editora Blucher, 2014. ISSN 2357-7282

DOI 10.5151/medpro-cihhs-10376 